ISSN. 2775-4324 (Online)

Journal of Physical Activity and Sports

Volume 2, Nomor 2, Agustus 2021, 280-287

Journal of Physical Activity and Sports

\title{
Penerapan model pembelajaran STAD dan TGT terhadap hasil belajar penjasorkes materi senam lantai roll belakang
}

\author{
Fajar Dwi Fadilah ${ }^{1}$, Donny Anhar Fahmi ${ }^{2}$, Ibnu Fatkhu Royana ${ }^{3}$ \\ Pendidikan Jasmani Kesehatan dan Rekreasi, Universitas PGRI Semarang \\ Jl. Dr. Cipto Semarang, Jawa Tengah, Indonesia \\ fajardwifadilahfadilah@gmail.com,pgsdikipdonny@gmail.com, ibnufatkhuroyana@gmail.com
}

\begin{abstract}
The background of this research is the ability of learning outcomes in the psychomotor, cognitive and affective aspects of both the XI IPS 1 grade students who are still many who are below KM. The learning method that will be used by researchers in conducting research is the learning model using the STAD and TGT models. The results showed: (1) there was an effect of the learning model on learning outcomes in class XI IPS 1 (STAD) as evidenced by the results of the paired simple $t$ test with a significant value of Sig. (2-tailed) $0.039>0.05$ and the average post-test graph value of learning outcomes. (2) there is an effect of the learning model on learning outcomes in class XI IPA 1 (TGT) as evidenced by the results of the paired simple $t$ test with a significant value of Sig. (2tailed) $0.039>0.05$ and the average post-test graph value of learning outcomes. The conclusions of this study indicate that the results of the study of the STAD or TGT learning model applied to class XI IPS 1 and class XI IPA 1.Even by simple paired simple $t$ test class XI IPS 1 Significance level: $\alpha=5 \%=0,05$ Testing Criteria: If Sig. (2-tailed) $>\alpha$ then H0 is accepted. For Class XI IPA 1 TGT Significance Level: $\alpha=5 \%=0.05$ Testing Criteria: If Sig. (2-tailed) $>\alpha$ then $\mathrm{H} 0$ is accepted.
\end{abstract}

Keywords: learning model, STAD and TGT, Physical Education learning outcomes

\begin{abstract}
Abstrak
Latar belakang penelitian ini adalah kemampuan hasil belajar pada aspek psikomotor, kognitif dan afektif baik dari siswa nilai kelas XI IPS 1 yang masih banyak yang di bawah kkm, Metode pembelajaran yang akan digunakan oleh peneliti dalam melakukan penelitian adalah model pembelajaran dengan menggunakan model STAD dan TGT Hasil penelitian menunjukkan: (1) terdapat pengaruh model pembelajaran terhadap hasil belajar pada kelas Kelas XI IPS 1 (STAD) dengan dibuktikan hasil paired simple t test nilai signifikasni Sig. (2-tailed) $0,039>0,05$ serta nilai post test grafik rata rata hasil belajar. (2) terdapat pengaruh model pembelajaran terhadap hasil belajar pada kelas Kelas XI IPA 1( TGT) dengan dibuktikan hasil paired simple t test nilai signifikasni Sig. (2-tailed) $0,039>0,05$ serta nilai post test grafik rata rata hasil belajar. Simpulan dari penelitian ini menunjukan bahwa Dari hasil penelitian model pembelajaran STAD atau TGT yang di terapkan pada kelas XI IPS 1 dan kelas XI IPA 1. Di buktikan dengan simple paired simple $t$ test kelas XI IPS 1 Taraf Signifikansi: $\alpha=5 \%=0,05$ Kriteria Pengujian : Jika Sig. (2-tailed) $>\alpha$ makaH0 diterima. Untuk Kelas XI IPA 1 TGT Taraf Signifikansi: $\alpha=5 \%=$ 0,05 Kriteria Pengujian : Jika Sig. (2-tailed) $>\alpha$ makaH0 diterima.
\end{abstract}

Kata kunci : Model pembelajaran, STAD dan TGT, Hasil belajar penjasorkes

\section{PENDAHULUAN}

Pendidikan jasmani olahraga dan kesehatan merupakan bagian integral dari pendidikan secara keseluruhan, bertujuan untuk mengembangkan aspek kebugaran jasmani, ketrampilan gerak, katrampilan berfikir kritis, ketrampilan sosial, penalaran stabilitas, emosional, tindakan moral, aspek pola hidup sehat dan pengenalan hidup bersih melalui aktivitas jasmani olahraga dan kesehatan terpilih yang di rencanakan secara sistematis dalam rangka mencapai tujuan pendidikan nasional (Munafi, M. 
A 2018:5) Undang-Undang No: 20 Tahun 2003 tentang Sistem Pendidikan Nasional yang menyebutkan bahwa pendidikan nasional berfungsi mengembangkan kemampuan dan membentuk watak serta peradaban bangsa yang bermartabat dalam rangka mencerdaskan kehidupan bangsa, bertujuan untuk mengembangkan potensi peserta didik agar menjadi insan yang beriman dan bertaqwa kepada Tuhan Yang Maha Esa, berakhlak mulia, sehat jasmani rohani, berilmu, cakap, kreatif, inovatif, mandiri, tanggung jawab, demokratis, menjunjung hak asasi manusia, serta mengamalkan Pancasila dan Undang Undang Dasar 1945 (Munafi, M. A 2018:5). Menurut departemen pendidikan nasional (2006:163), Pendidikan Jasmani Olahraga dan Kesehatan merupakan bagian integral dari pendidikan secara keseluruhan, bertujuan untuk mengembangkan aspek kebugaran jasmani, ketrampilan gerak, ketrampilan berpikir kritis, ketrampilan sosial, penalaran, stabilitas emosional, tindakan, moral, aspek pola hidup sehat dan pengenalan lingkungan bersih melalui aktivitas jasmani olahraga dan kesehatan. Belajar dan pembelajaran berlangsung dalam suatu proses yang dimulai dengan perencanaan berbagai komponen dan perangkat pembelajaran agar dapat diimplementasikan dalam bentuk interaksi yang edukatif dan diakhiri dengan evaluasi untuk mengukur dan menilai tingkat pencapaiaan tujuan pembelajaran yang diharapakan Belajar dan pembelajaran merupakan suatu proses yang kompleks dengan menyatukan komponen komponen yang memiliki karakteristik tersendiri yang secara terintegrasi saling terkait dan mempengaruhi untuk mencapai tujuan atau kompetensi yang diharapkan Komponen komponen pembelajaran yang dimaksud mencakup tujuan materi metode media dan sumber evaluasi peserta didik guru dan lingkungan. Menurut Muh Sain Hanafy 2014:67. Belajar dan pembelajaran merupakan aktivitas yang terencana untuk mencapai tujuan tertentu yang dicirikan dengan keterlibatan sejumlah komponen yang saling terkait satu sama lain. Komponen komponen dalam belajar dan pembelajaran yang dimaksud disebut perangkat pembelajaran yang terdiri atas rencana pelaksanaan alat pembelajaran yang mencakup metode media dan sumber belajar serta alat evaluasi baik berupa tes maupun non tes Belajar dan pembelajaran baik sebagai proses maupun sebagai sistem telah mendapat perhatian dari para ahli dengan sudut pandang yang berbeda sesuai dengan bidang keahliaan masing masing sehingga melahirkan konsep dan teori belajar dan pembelajaran yang beragam. Proses pembelajaran Penjasorkes di tekankan pada pengembangan individu secara menyeluruh dalam arti pengembangan moral spiritual, kebugaran jasmani, dan aktivitas gerak fisik sebagai sarana untuk merealisasikan tujuan pembelajaran. Penjasorkes tidak di arahkan untuk menguasai cabang olahraga namun lebih mengutamakan proses perkembangan motorik siswa. Dalam proses pembelajaran penjasorkes, guru diharapkan mengajarkan berbagai ketrampilan gerak dasar teknik dan strategi permainan dan olahraga, internalisasi nilai nilai sportivitas, jujur, kerja sama dan pembiasaan pola hidup sehat. (Sudarmianti, D.A 2018:2)

Aktivitas belajar sangat beraneka ragam jenisnya, untuk itu para ahli mengadakan klasifikasi atau pengelompokan terhadap jenis-jenis aktivitas belajar tersebut. Menurut Paul D Dierich (dalam hamalik 2008:90) membagi kegiatan belajar dalam 8 kelompok yaitu kegiatan visual, audio, lisan, 
menulis, menggambarakan metrik, mental dan emosioanal, namun dalam penelitiaan ini peneliti hanya meneliti 6 kegiatan aktivitas belajar yaitu visual, audio, lisan, mental metrik, dan emosional. Guling belakang yaitu gerakan senam yang dilakukan dengan posisi berguling ke arah belakang badan, dimulai dari panggul belakang, pinggang, punggung, dan terakhir tengkuk. guling belakang terdiri dari kaki tekuk dan guling belakang kaki lurus (Harsono \& Sudarso, 2018). Sedangkan Motion, Volume 10, No.2, September 201996 menurut Priastuti guling belakang adalah gerakan badan berguling ke arah belakang melalui bagian belakang badan mulai dari panggul bagian belakang, pinggang, punggung, dan tengkuk (Priastuti, 2015). Adapun model pembelajaran teknik dasar guling belakang: (1) model pembelajaran I latihan menolak badan ke belakang, (2) model pembelajaran II gerakan guling belakang dengan mengayunkan badan, (3) model pembelajaran III guling belakang awalan duduk, (4) model pembelajaran IV guling belakang awalan jongkok, (5) model pembelajaran V melakukan guling belakang awalan berdiri, sedangkan Model Pembelajaran Cara membantu untuk guling belakang meliputi: (1) model pembelajaran I cara membantu teknik menolak badan ke belakang, (2) model pembelajaran II cara membantu tekni mengayunkan badan, (3) model pembelajaran III cara membantu teknik guling belakang awalan duduk, (4) model pembelajaran IV cara membantu guling belakang dengan awalan jongkok, dan (5) model pembelajaran V cara membantu teknik guling belakang dengan awalan berdiri.

Menurut Trianto (2010:68) model pembelajaran kooperatif tipe STAD merupakan "salah satu tipe pembelajaran kooperatif dengan menggunakan kelompok-kelompok kecil dengan jumlah anggota tiap kelompok 4-5 orang siswa secara heterogen". Slavin menyatakan bahwa dalam pembelajaran STAD siswa ditempatkan dalam beberapa kelompok atau tim, masing-masing terdiri atas 4 atau 5 siswa yang heterogen, baik jenis kelamin, ras, etnik maupun kemampuannya (tinggi, sedang, rendah). Guru menyajikan pelajaran, dan kemudian siswa bekerja dalam tim mereka memastikan bahwa seluruh anggota tim telah menguasai pelajaran tersebut. Secara individual atau tim, setiap minggu atau tiap dua minggu dilakukan tes untuk mengetahui penguasaan tiap siswa dan pada saat tes mereka tidak diperbolehkan saling membantu. Kemudian tiap siswa dan tim yang memperoleh skor sempurna di beri penghargaan untuk memicu semangat belajar.

Berdasarkan observasi pada tanggal 2 September 2020 di kelas XI IPS 1 dan kelas XI IPA 1 dan Aisyah perempuan di SMA Muhammadiyah 1 Cilacap kelas XI IPS 1 STAD dan XI IPA 1 TGT di dapat kurangnya motivasi dalam mengikuti pembelajaran PJOK pembelajaran materi roll belakang. Hal imi dibuktikan dengan hasil nilai dari siswa dan siswi masih banyak yang dibawah standar KKM (Kriteria Ketuntasan Minimal). 
Tabel 1. Hasil Tes Kemampuan Belajar Melakukan Gerakan Roll Belakang siswa - siswa kelas XI Sma Muhammadiyah 1 Cilacap

\begin{tabular}{|c|c|c|c|c|c|c|}
\hline \multirow{2}{*}{ No } & \multirow{2}{*}{ Kelas } & \multicolumn{3}{|c|}{$\begin{array}{c}\text { Rata rata Hasil Belajar permainan } \\
\text { bola besar kelas VII }\end{array}$} & \multirow{2}{*}{$\begin{array}{l}\text { Rata-Rata } \\
\text { Nilai }\end{array}$} & kkm \\
\hline & & Afektif & Kognitif & Psikomotor & & \multirow{3}{*}{75} \\
\hline 1. & Kelas XI IPS 1 & 70 & 55 & 58 & 61 & \\
\hline 2. & Kelas XI IPA 1 & 68 & 53 & 55 & 58 & \\
\hline
\end{tabular}

Sumber : nilai rata rata hasil belajar kelas XI di Sma Muhammadiyah 1 Cilacap

\section{METODE PENELITIAN}

Penelitian ini menggunakan metode kuantitatif dengan desain eksperimen dalam rancangann probability sampling, teknik pengambilan sampel purposive sampling. Probability sampling adalah teknik pengambilan sampel yang memberikan peluang yang sama bagi setiap unsur (anggota) populasi untuk di pilih menjadi anggota sampel.

Desain One Group Prestest Postest Design dapat digambarkan seperti berikut:

\section{$\mathrm{O} 1 \mathrm{X} \mathrm{O} 2$}

$$
\begin{aligned}
& \text { Keterangan: } \\
& \mathrm{O} 1=\text { Nilai pretest (sebelum di beri diklat) } \\
& \mathrm{O} 2=\text { Nilai postest (setelah di beri diklat) } \\
& \mathrm{X}=\text { Treatment }
\end{aligned}
$$

Teknik pengumpulan data yang saya lakukan pertama adalah peneliti melakukan penilian tes awal berdasarkan aspek kognitif, psikomotorik dan afektif terkait materi pembelajaran dengan Instrumen Rencana pelaksanaan pembelajaran senam lantai roll belakang.

Tahap pertama dalam peneliti dalam melakukan penelitian ini di lakukan pre test hasil belajar pada model pembelajaran STAD pada kelas XI IPS 1 sesuai dengan metode One Group Pre Test Post Test Design kemudian di lakukan treatment dengan pembelajaran tersebut di lanjutkan dengan post test. kemudian pada kelas yang sama . Di lakukan pre test hasil belajar pada model pembelajaran TGT pada kelas XI IPS 1 sesuai dengan metode One Group Pre Test Post Test Design kemudian di lakukan treatment dengan pembelajaran tersebut di lanjutkan dengan post test. Dalam melakukan penelitian ini di lakukan pre test hasil belajar pada model pembelajaran TGT pada kelas XI IPA 1 sesuai dengan metode One Group Pre Test Post Test Design kemudian di lakukan treatment dengan pembelajaran 
tersebut di lanjutkan dengan post test. kemudian pada kelas yang berbeda. . Di lakukan pre test hasil belajar pada model pembelajaran STAD pada kelas XI IPA 1 sesuai dengan metode One Group Pre Test Post Test Design kemudian di lakukan treatment dengan pembelajaran tersebut di lanjutkan dengan post test.

Tahap kedua peneliti melakuakan Treatment pada sekolah SMA Muhammadiyah 1 Cilacap kelas XI IPS 1 dan Kelas XI IPA 1 dengan menggunakan program pembelajaran penjasorkes sesuai dengan RPP dan silabus dan menggunakan metode pembelajaran STAD dan TGT Tahap ketiga yaitu peneliti melakukan tes akhir hasil belajar bola besar yang meliputi aspek kognitif, psikomotorik dan efektif (sama dengan tes awal ) dengan instrument RPP.

Sampel yang di gunakan yaitu seluruh siswa kelas XI siswa laki laki dan perempuan yang terdiri dari populasi berjumlah 50 siswa dan terbagi menjadi 2 kelas.

\section{HASIL DAN PEMBAHASAN}

Penelitian ini bertujuan untuk mengetahui seberapa besar pengaruh model pembelajaran STAD dan TGT dalam permainan senam lantai roll belakang, jika diberikan dengan pembelajaran roll belakang dengan cara menggunakan model pembelajaran STAD dan TGT pada siswa kelas XI SMA Muhammadiyah 1 Cilacap.

Data dalam penelitian ini meliputi pre-test, treatment dan pot-test. Hasil penelitian pada kelompok eksperimen disajikan sebagai berikut:

Berikut adalah penyajian data perbandingan nilai psikomotor, kognitif dan afektif yang dimiliki oleh setiap kelas XI SMA Muhammadiyah 1 Cilacap melalui grafik:

Gambar 1. Grafik hasil belajar kelas XI IPS 1 STAD

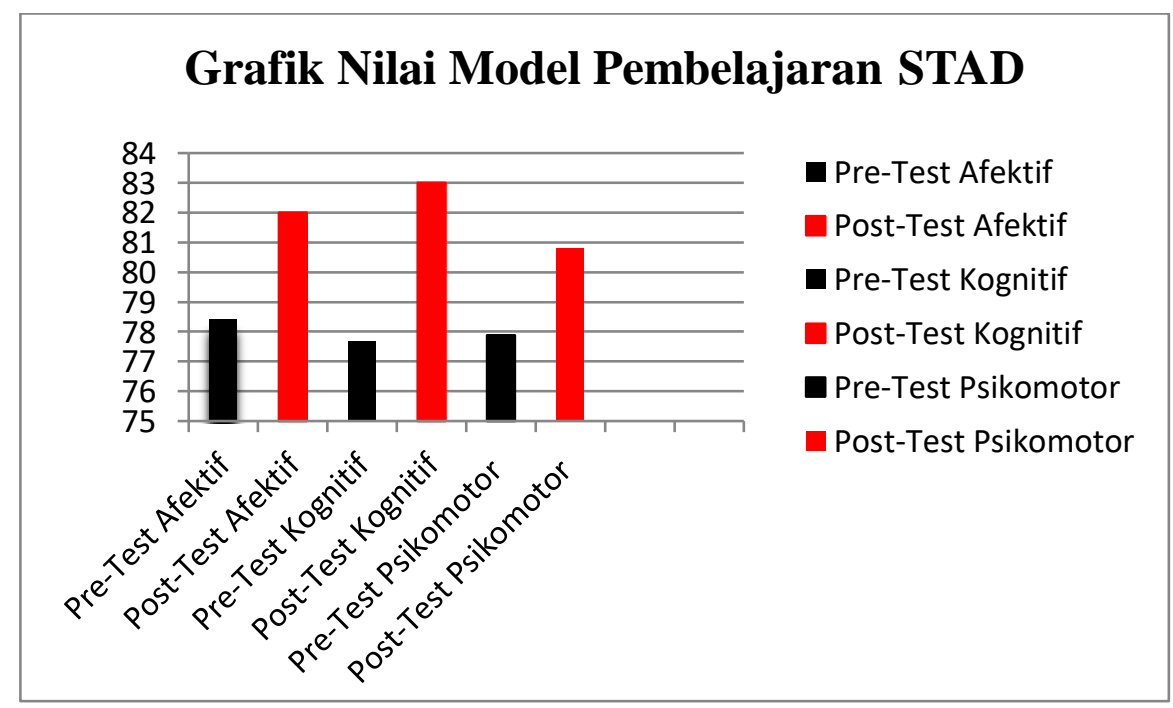


Gambar 2. Grafik hasil belajar kelas XI IPS 1 TGT

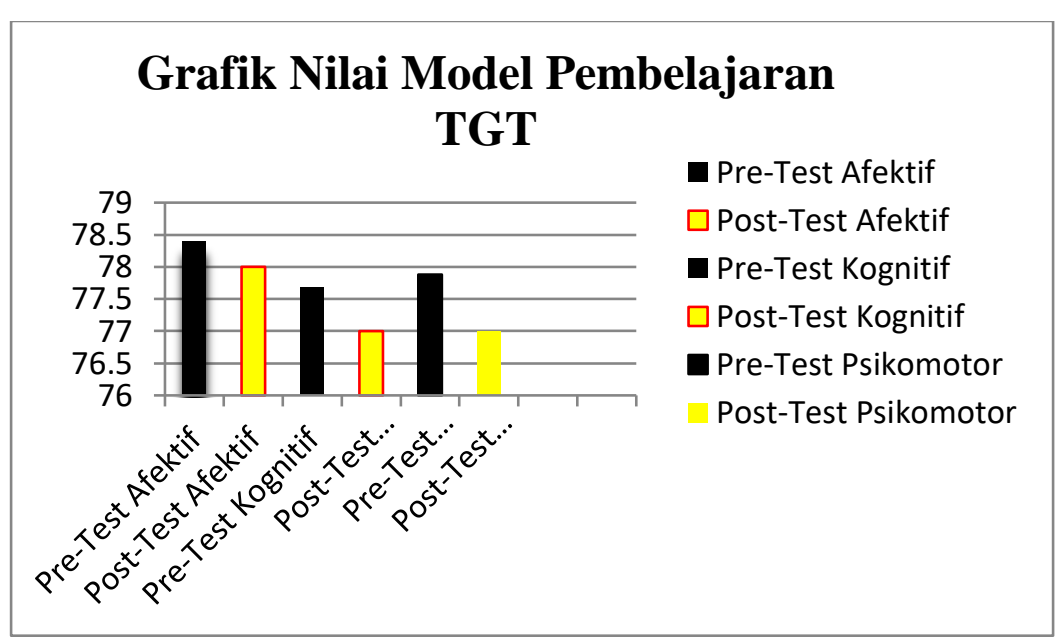

Gambr 3. Grafik model pembelajaran STAD kelas IPA 1

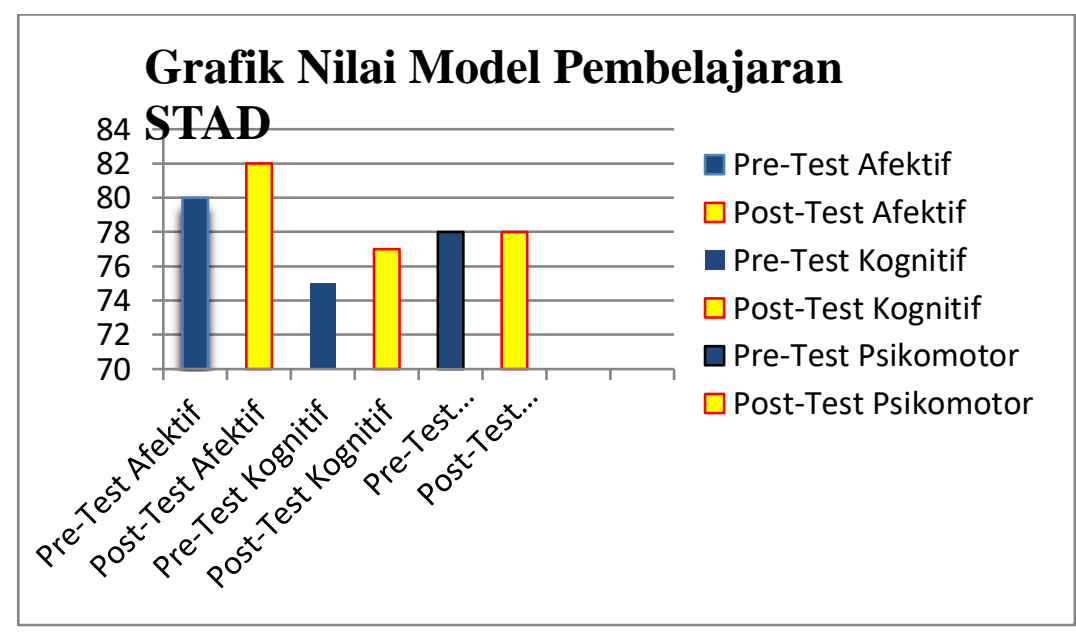

Gambar 4. Grafik Presentase kelas XI IPA 1 TGT

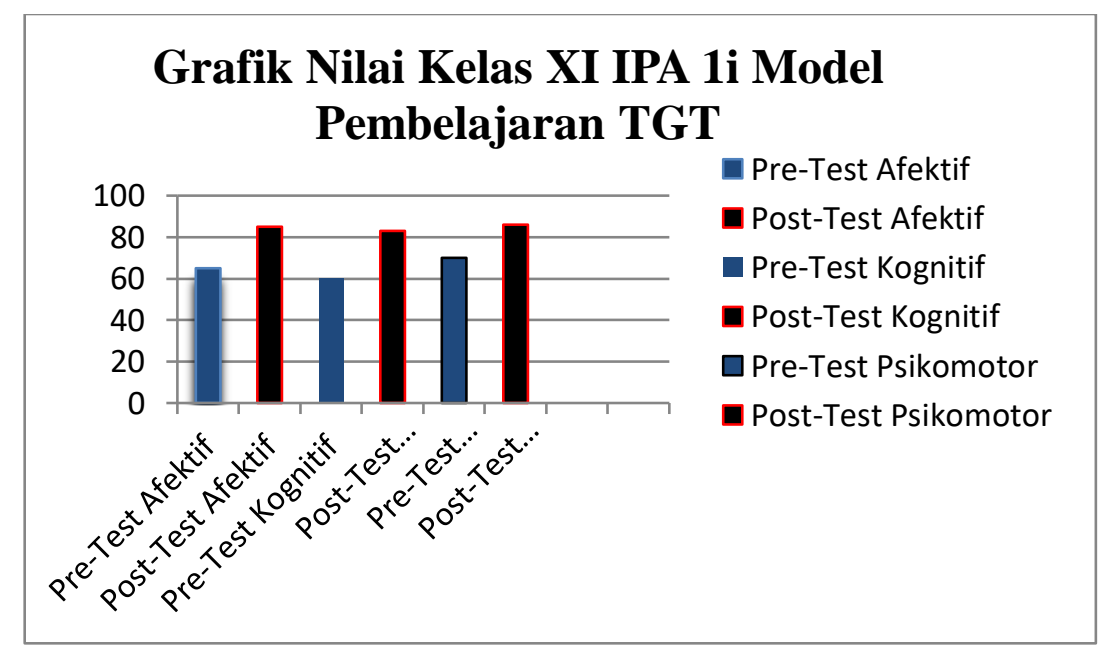




\section{Analisis Data Akhir}

Model Pembelajaran STAD

\section{Uji Normalitas}

a) Nilai Hasil Belajar Kelas XI IPA 1 dan XI IPS 1

Dari output SPSS dapat diketahui semua nilai Asymp. Sig. (2tailed) dari 3 aspek variabel diatas 0,05 dengan nilai 0,945. Jadi, dapat disimpul bahwa hasil data Uji Normalitas Kuesioner Model Pembelajaran STAD tersebut berdistribusi normal.

b) Uji Normalitas Nilai Hasil Belajar Kelas XI IPS 1 dan Kelas XI IPA 1

Dari output SPSS dapat diketahui semua nilai Asymp. Sig. (2tailed) dari 3 aspek variabel diatas 0,05 dengan nilai 0,983. Jadi, dapat disimpul bahwa hasil data Uji Normalitas Kuesioner Model Pembelajaran TGT tersebut berdistribusi normal.

\section{Uji Homogenitas}

a) Nilai Hasil Belajar Kelas XI IPS 1 dan Kelas XI IPA 1 STAD

Berdasarkan uji Homogenitas diketahui nilai Sig. adalah 0,510>0,05 maka data tersebut homogen. Jadi dapat disimpulkan bahwa varian nilai praktik materi senam lantai roll belakang.

b) Nilai Hasil Belajar Kelas XI IPA 1 dan Kelas XI IPS 1 TGT

Test of Homgenity of Variance diketahui nilai Sig. adalah 0,510>0,05 maka data tersebut homogen. Jadi dapat disimpulkan bahwa varian nilai praktik materi senam lantai roll belakang.

\section{Uji T Berpasangan/ Paired Sample T Test}

a) Nilai Hasil Belajar Kelas XI IPA 1 dan Kelas XI IPS 1 STAD

Pada hasil hipotesis didapat nilai Sig. (2-tailed $)=0,002$. Karena nilai Sig. (2-tailed $)<\alpha$, maka $\mathrm{H}_{0}$ ditolak. Artinya ada perbedaan rata-rata nilai afektif siswa kelas XI IPS 1 dan Kelas XI IPA 1 sebelum dengan sesudah perlakuan.

b) Kelas XI IPS 1 (TGT) dan Kelas XI IPA 1 (TGT)

Pada hasil hipotesis aspek afektif didapat nilai Sig. (2-tailed) $=0,000$. Karena nilai Sig. (2tailed $)<\alpha$, maka $\mathrm{H}_{0}$ ditolak. Artinya ada perbedaan rata-rata nilai afektif siswa kelas model pembelajaran TGT kelas XI IPS 1 (pre test) dan XI IPA 1 (Post test).

\section{KESIMPULAN}

Simpulan dari penelitian ini menunjukan bahwa Dari hasil penelitian model pembelajaran STAD atau TGT yang di terapkan pada kelas XI IPS 1 dan kelas XI IPA 1. Di buktikan dengan simple paired simple $t$ test kelas XI IPS 1 Taraf Signifikansi: $\alpha=5 \%=0,05$ Kriteria Pengujian : Jika Sig. (2tailed) $>\alpha$ makaH0 diterima. Untuk Kelas XI IPA 1 TGT Taraf Signifikansi: $\alpha=5 \%=0,05$ Kriteria Pengujian : Jika Sig. (2-tailed) $>\alpha$ makaH0 diterima. Maka dapat di simpulkan bahwa model STAD adalah model yang tepat untuk di terapkan pada kelas XI IPS 1 untuk model pembelajaran STAD. 
Kemudian pembelajaran yang tepat bagi kelas XI IPA 1 pembelajaran untuk model pembelajaran TGT. Saran yang dapat peneliti kepada guru penjasorkes adalah Guru penjasorkes dapat menerapkan metode

STAD sebagai alternatif kegiatan pembelajaran bagi kelas laki laki dan TGT untuk kelas perempuan.

\section{DAFTAR PUSTAKA}

Mendikbud. (2016). Menteri Pendidikan dan Kebudayaan No. 22. Jakarta: Mendikbud.

Mardiana, Dkk. (2008). PJOK merupakan wadah pengembangan sikap. Jakarta: Grafindo.

Khakim. (2014). Pendidikan Jasmani merupakan bagian integral melalui aktivitas psikomotor. Yogyakarta: Lentera.

Suherman. (2018). Tujuan pendidikan jasmani bermuara pada pribadi adaptif. Yogyakarta: Jaya Abadi.

Prambudi. (2014). Metode merupakan upaya guna untuk mencapai tujuan optimal. Bandung: Alfabeta.

Kunandar. (2011). Langkah Mudah Penelitian Tindakan Kelas sebagai pengembangan Profesi Guru. Jakarta: Hijau.

Mulyasa. (2014). Pembelajaran menghasilkan insane yang produktif, kreatif dan inovatif. Bandung: Alfabeta.

Dr. Rusman M. Pd. (2012). Model-model pembelajaran mengembangkan Profesional Guru. Semarang: Garfindo.

Sugiyono. (2016). Metode Penelitian Manajemen. Bandung: Alfabeta.. 